\title{
Grape pomace as a source of phenolic compounds and diverse bioactive properties
}

\author{
Carla M. Peixoto ${ }^{\mathrm{a}, \mathrm{b}}$, Maria Inês Dias ${ }^{\mathrm{a}}$, Maria José Alves $^{\mathrm{a}}$, Ricardo C. Calhelha ${ }^{\mathrm{a}}$, Lillian Barros ${ }^{\mathrm{a}}$, \\ Simão P. Pinho ${ }^{\mathrm{b}}$, Isabel C.F.R. Ferreira ${ }^{\mathrm{a}, *}$

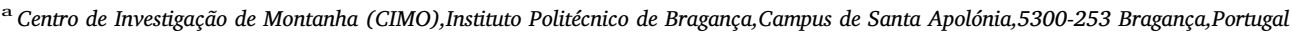 \\ ${ }^{\mathrm{b}}$ Associate Laboratory LSRE-LCM, Departamento de Tecnologia Química e Biológica, Instituto Politécnico de Bragança, Campus de Santa Apolónia, $5300-253$ Bragança, \\ Portugal
}

\section{A R T I C L E I N F O}

\section{Keywords:}

Vitis vinifera $\mathrm{L}$.

Grape pomace

Bio-residues

Phenolic compounds

Bioactivities

\begin{abstract}
A B S T R A C T
The bio-residues resulting from the wine industry (grape pomace made up of skins, seeds and stems) are often undervalued but constitute a potential source of bioactive phenolic compounds that can be applied in several industries. In this context, the aim of the present study was to evaluate the phenolic profile of Vitis vinifera L. grape pomace (skins, seeds and their mixture), and correlate them with its antioxidant, cytotoxic and antibacterial activities. The seeds showed the highest amount of phenolic compounds and also the highest antioxidant, cytotoxic and antibacterial activities. The skins revealed the highest levels of anthocyanins and $p$ coumaric acid hexoside. Strong correlations were observed between the presence of phenolic compounds and all the bioactivities studied. These by-products are good sources of phenolic compounds with high antioxidant and antibacterial activity, and also presenting a moderate cytotoxicity activity. These added-value by-products have great applicability in food, pharmaceutical and cosmetic industries.
\end{abstract}

\section{Introduction}

Vitis vinifera L. is a grapevine species from the Vitaceae family, which comprises a huge variety of white (Chardonnay, Pinot blanc, Gewürztraminer, Comtessa, Noblessa) and red (Pinot noir, Cabernet Sauvignon, Cabernet franc, Merlot, Petit Verdot) grapes (Rodríguez Montealegre, Romero Peces, Chacón Vozmediano, Martínez Gascueña, \& García Romero, 2006; Santos-Buelga, Francia-Aricha, \& EscribanoBailón, 1995; Terral et al., 2010). In recent years, the by-products of wine making and the agricultural residues of plant origin have attracted considerable attention as sources of bioactive phenolic compounds, that are used for various purposes in cosmetic, pharmaceutical and food industries (Makris, Boskou, \& Andrikopoulos, 2007). During wine production tons of grape pomace are obtained, which is essentially made up of skins, seeds and stems. These components, particularly the seeds, are rich in phenolic compounds known as antioxidant, antitumor, anti-aging, anti-microbial and anti-inflammatory agents (Xia et al., 2010; Yu \& Ahmedna, 2013).

In general, phenolic compounds found in wine and grapes can be classified in three main groups, phenolic acids (hydroxybenzoic and hydroxycinnamic acids), flavonoids (catechins, flavonols and anthocyanins) and proanthocyanidins. Genetic factors, environmental conditions and the degree of plant maturation widely influence the content in these compounds (Melo et al., 2006; Yu \& Ahmedna, 2013). Previous studies also showed the potential of grape pomace phenolic compounds to be used as preservatives, they prevent lipid oxidation and suppress the growth of some bacterial strains, such as Staphylococcus aureus, Streptococcus mutans and Escherichia coli (Yu \& Ahmedna, 2013). The antitumor activity of grape pomace polyphenols has also been reported within their preventive effects in several diseases, which led to the commercialization of different dietary food supplements rich in polyphenols (Caleja, Ribeiro, Barreiro, \& Ferreira, 2017; Scalbert, Manach, Morand, Rémésy, \& Jiménez, 2005).

Previous studies have established a relation between the presence of phenolic compounds and some bioactivities exhibited by red grapes varieties. For instance, Bartolomé, Nuñez, Monagas, and GómezCordovés (2004) and Murthy, Singh, and Jayaprakasha (2002) described the antioxidant activity of red grapes skins from Vitis vinifera var. Cabernet Sauvignon, Graciano and Tempranillo from Spain and var. Bangalore blue from Indian states, respectively. Scalbert et al. (2005) related the presence of polyphenols with tumor cells' apoptosis. On the other hand, Jayaprakasha et al. (2003) and Anastasiadi, Chorianopoulos, Nychas, and Karoutounian (2009), reported the antimicrobial activity of grape extracts (var. Bangalore blue and var.

\footnotetext{
* Corresponding author

E-mail address: iferreira@ipb.pt (I.C.F.R. Ferreira).
} 
Mandilaria, Voidomato, Asyrtiko and Aidani, respectively) against gram positive and negative bacteria.

In this context, the aim of the present study was to characterize Vitis vinifera grape pomace (skins, seeds and their mixture) in terms of the phenolic profile and correlation with biological properties namely antioxidant, cytotoxic and antibacterial activities.

\section{Materials and methods}

\subsection{Standards and reagents}

Acetonitrile (99.9\%) was of HPLC grade from Fisher Scientific (Lisbon, Portugal). Phenolic standards $((+)$-catechin, delphinidin, (-)-epicatechin, gallic acid, malvidin, peonidin-3-O-glucoside, $p$-coumaric acid, quercetin-3-O-glucoside) were from Extrasynthèse (Genay, France). Sulforhodamine B, trypan blue, trichloroacetic acid (TCA), tris (hydroxymethyl)aminomethane (Tris), Trolox (6-hydroxy-2,5,7,8-tetramethylchroman-2-carboxylic acid) and formic acid were purchased from Sigma-Aldrich (St. Louis, MO, USA). Dulbecco's modified Eagle's medium (DMEM), hank's balanced salt solution (HBSS), foetal bovine serum (FBS), L-glutamine, trypsin-EDTA, penicillin/streptomycin solution $(100 \mathrm{U} / \mathrm{ml}$ and $100 \mathrm{mg} / \mathrm{ml}$, respectively) were purchased from Hyclone (Logan, Utah, USA). 2,2-Diphenyl-1-picrylhydrazyl (DPPH) was obtained from Alfa Aesar (Ward Hill, MA, USA). All other general laboratory reagents were purchased from Panreac Química S.L.U. (Barcelona, Spain). Water was treated in a Milli-Q water purification system (TGI Pure Water Systems, Greenville, SC, USA).

\subsection{Preparation of the samples}

Fermented grape pomace, a by-product of the winery industry, was provided by Alijó Cooperative Winery (Vila Real, Portugal). The skins and seeds of the grape pomace were manually separated in order to obtain three different samples: i) mixture; ii) skins and iii) seeds (Fig. 1). These fractions were uniformly distributed on trays and dehydrated in a forced-air-drying oven (Imperial IV Microprocessor Oven, Lab-Line Instruments, Inc., Melrose Park, III) at $50{ }^{\circ} \mathrm{C}$ until $7.0 \%$ of moisture was reached.

\subsection{Analysis of the phenolic compounds}

The phenolic profile was determined by LC-DAD-ESI/MSn (Dionex Ultimate 3000 UPLC, Thermo Scientific, San Jose, CA, USA).

\subsubsection{Non-anthocyanin compounds}

To prepare the hydromethanolic extracts, $1 \mathrm{~g}$ of each sample was submitted to extraction with a methanol/water mixture (80:20, $v / v$; $30 \mathrm{ml}$ ) at $25^{\circ} \mathrm{C}$ and $150 \mathrm{rpm}$ during $1 \mathrm{~h}$, followed by filtration through a
Whatman filter paper No. 4. Afterwards, the residue was extracted with one additional portion of the hydromethanolic mixture and the combined extracts were evaporated under reduced pressure (rotary evaporator Büchi R-210, Flawil, Switzerland).

These compounds were separated and identified as previously described by Bessada, Barreira, Barros, Ferreira, and Oliveira (2016). The obtained extracts were re-dissolved at a concentration of $5 \mathrm{mg} / \mathrm{ml}$ with a methanol/water $(80: 20, v / v)$ mixture. For the double online detection, 280, 330 and $370 \mathrm{~nm}$ were used as preferred wavelengths for the diode array detector (DAD) and in a mass spectrometer (MS) connected to HPLC system via the DAD cell outlet. The MS detection was performed in negative mode, using a Linear Ion Trap LTQ XL mass spectrometer (ThermoFinnigan, San Jose, CA, USA) equipped with an ESI source.

\subsubsection{Anthocyanin compounds}

Each powdered sample $(1 \mathrm{~g})$ was extracted with $30 \mathrm{ml}$ of methanol containing $0.5 \%$ trifluoroacetic acid (TFA), and filtered through a Whatman No. 4 paper. The residue was then re-extracted twice with additional $30 \mathrm{ml}$ portions of $0.5 \%$ TFA in methanol. The combined extracts were evaporated at $35^{\circ} \mathrm{C}$ to remove the methanol, and re-dissolved at a concentration of $5 \mathrm{mg} / \mathrm{ml}$ in $80 \%$ acidified methanol with TFA $(0.01 \%)$. These compounds were separated and identified as previously described by Gonçalves et al. (2017). For the double online detection, $520 \mathrm{~nm}$ was used as preferred wavelengths for DAD and in a MS connected to HPLC system via the DAD cell outlet. The MS detection was performed in positive mode, using a Linear Ion Trap LTQ XL mass spectrometer (ThermoFinnigan, San Jose, CA, USA) equipped with an ESI source.

The identification of the phenolic compounds (non-anthocyanins and anthocyanins) was performed based on their chromatographic behaviour and UV-vis and mass spectra by comparison with standard compounds, when available, and data reported in the literature giving a tentative identification. Data acquisition was carried out with Xcalibur ${ }^{\circledR}$ data system (ThermoFinnigan, San Jose, CA, USA). For quantitative analysis, a calibration curve for each available phenolic standard was constructed based on the UV signal. For the identified phenolic compounds for which a commercial standard was not available, the quantification was performed through the calibration curve of the most similar available standard: catechin $\left(y=84539 x+269612, R^{2}=0.991\right)$; delphinidin $(y=557274 x$ $\left.+126.24, \quad R^{2}=0.999\right) ; \quad(-)$-epicatechin $\quad(y=28512 x+2000000$, $\left.R^{2}=0.999\right) ;$ gallic acid $\left(y=280379 x+119556, R^{2}=0.998\right)$; malvidin $\left(y=477014.9 x+38.38, R^{2}=0.999\right) ; p$-coumaric acid $(y=301950 \mathrm{x}$ $\left.+6967, R^{2}=0.999\right) ;$ peonidin-3-O-glucoside $(y=537017 x-71.47$, $\left.R^{2}=0.999\right) \quad$ and quercetin-3-O-glucoside $\quad(y=23853 x+343376$, $R^{2}=0.999$ ). The results were expressed as $\mu \mathrm{g} / \mathrm{g}$ extract.
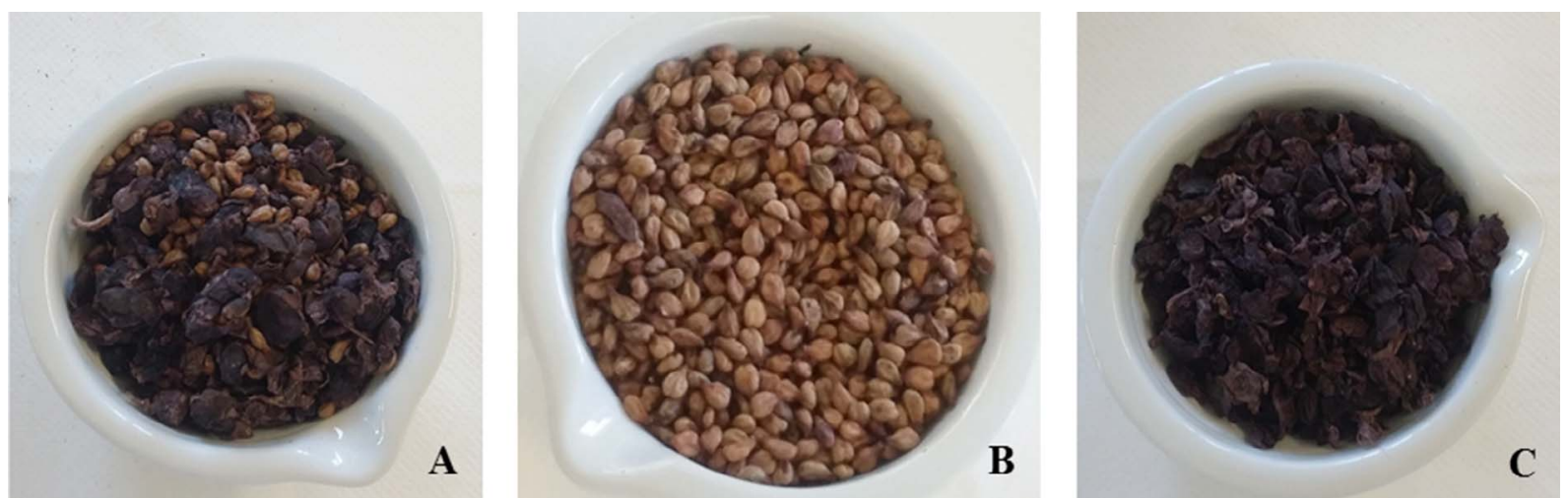

Fig. 1. Grape pomace mixtures (A), seeds (B) and skins (C). 
Table 1

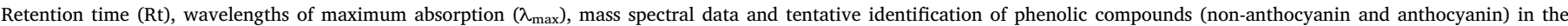
hydromethanolic extracts of grape pomace.

\begin{tabular}{|c|c|c|c|c|c|}
\hline Peak & Rt (min) & $\lambda_{\max }(\mathrm{nm})$ & {$[\mathrm{M}-\mathrm{H}]^{-}(m / z)$} & $\operatorname{MS}^{2}(m / z)$ & Tentative identification \\
\hline \multicolumn{6}{|c|}{ Non-anthocyanin phenolic compounds } \\
\hline 1 & 4.74 & 272 & 169 & $125(100)$ & Gallic acid \\
\hline 2 & 5.24 & 276 & 331 & $169(100), 125(3)$ & Galloyl glucose \\
\hline 3 & 8.52 & 277 & 289 & $245(42), 203(36), 187(27), 161(13), 137(28)$ & Catechin \\
\hline 4 & 10.26 & 280 & 577 & $451(18), 425(82), 407(91), 289(100), 287(18)$ & $\beta$-Type (epi)catechin dimer \\
\hline 5 & 11.70 & 280 & 289 & 245(39),203(30),187(17),161(13),137(17) & Epicatechin \\
\hline 6 & 13.14 & 279 & 865 & $739(8), 713(7), 695(20), 577(45), 575(8), 425(20), 407(30), 289(11), 287(25)$ & $\beta$-Type (epi)catechin trimer \\
\hline 7 & 13.97 & 311 & 325 & $163(100)$ & $p$-Coumaric acid hexoside \\
\hline 8 & 14.19 & 280 & 1153 & $865(3), 863(14), 577(7), 575(5), 289(14), 287(5)$ & $\beta$-Type (epi)catechin tetramer \\
\hline 9 & 15.44 & 308 & 325 & $163(100)$ & $p$-Coumaric acid hexoside \\
\hline 10 & 15.59 & 279 & 577 & $289(50), 245(100), 204(36)$ & $\beta$-Type (epi)catechin dimer \\
\hline 11 & 16.45 & 280 & 865 & $739(8), 713(7), 695(20), 577(45), 575(8), 425(20), 407(30), 289(11), 287(25)$ & $\beta$-Type (epi)catechin trimer \\
\hline 12 & 17.13 & 280 & 865 & $739(8), 713(7), 695(20), 577(45), 575(8), 425(20), 407(30), 289(11), 287(25)$ & $\beta$-Type (epi)catechin trimer \\
\hline 13 & 17.56 & 278 & 577 & $451(18), 425(82), 407(91), 289(100), 287(18)$ & $\beta$-Type (epi)catechin dimer \\
\hline 14 & 17.84 & 280 & 1153 & $865(3), 863(14), 577(7), 575(5), 289(14), 287(5)$ & $\beta$-Type (epi)catechin tetramer \\
\hline 15 & 19.91 & 280 & 1153 & $865(3), 863(14), 577(7), 575(5), 289(14), 287(5)$ & $\beta$-Type (epi)catechin tetramer \\
\hline 16 & 21.17 & 353 & 477 & $301(100)$ & Quercetin-glucoronide \\
\hline 17 & 21.61 & 354 & 493 & $331(100)$ & Laricitrin-3-O-galactoside \\
\hline 18 & 21.77 & 353 & 463 & $301(100)$ & Quercetin-3-O-glucoside \\
\hline 19 & 23.64 & 353 & 507 & $345(100)$ & Syringetin-3-O-galactoside \\
\hline 20 & 24.02 & 313 & 655 & $509(15), 501(52), 475(68), 347(13), 329(100), 314(12), 303(5)$ & $\begin{array}{l}\text { Laricitrin-3-O-rhamnose-7-O-trihydroxycinnamic } \\
\text { acid }\end{array}$ \\
\hline 21 & 24.52 & 312 & 745 & $653(22), 419(38), 345(100)$ & Syringetin rutinoside derivative \\
\hline \multicolumn{6}{|c|}{ Anthocyanin phenolic compounds } \\
\hline 22 & 22.8 & 534 & 493 & $331(100)$ & Malvidin-hexoside \\
\hline 23 & 37.4 & 532 & 535 & $331(100)$ & Malvidin-acetylhexoside \\
\hline 24 & 38.1 & 536 & 611 & $303(100)$ & Delphinidin-rutinoside \\
\hline 25 & 40.4 & 536 & 655 & $331(100)$ & Malvidin-dihexoside \\
\hline 26 & 41.3 & 532 & 625 & $317(100)$ & Petunidin-rutinoside \\
\hline 27 & 43 & 524 & 609 & $301(100)$ & Peonidin-rutinoside \\
\hline 28 & 44.2 & 532 & 639 & $331(100)$ & Malvidin-rutinoside \\
\hline
\end{tabular}

\subsection{Evaluation of the bioactive properties}

\subsubsection{Antioxidant activity}

The extracts previously described were re-dissolved in methanol/ water $(80: 20, v / v)$ in order to obtain stock solutions $(10 \mathrm{mg} / \mathrm{ml})$, which were further diluted to obtain a range of working concentrations to evaluate the antioxidant activity. DPPH radical-scavenging activity was evaluated by using an ELX800 microplate reader (Bio-Tek Instruments, Inc; Winooski, USA), and calculated as a percentage of DPPH discolouration measured at $515 \mathrm{~nm}$. Reducing power was evaluated by the capacity to convert $\mathrm{Fe}^{3+}$ into $\mathrm{Fe}^{2+}$, measuring the absorbance at $690 \mathrm{~nm}$ in the microplate reader mentioned above. The inhibition of $\beta$ carotene bleaching was evaluated through the $\beta$-carotene/linoleate assay, by applying the following equation: $\beta$-carotene absorbance after $2 \mathrm{~h}$ of assay/initial absorbance) $\times 100$, the absorbance was measured at $470 \mathrm{~nm}$. The lipid peroxidation inhibition was evaluated in porcine brain homogenates by the decrease in thiobarbituric acid reactive substances (TBARS); the colour intensity of the malondialdehyde-thiobarbituric acid (MDA-TBA) was measured by its absorbance at $532 \mathrm{~nm}$ (Barros et al., 2013). The final results were expressed as EC $_{50}$ values, sample concentration providing $50 \%$ of antioxidant activity or 0.5 of absorbance in the reducing power assay. Trolox was used as positive control.

\subsubsection{Cytotoxic activity}

The methanol/water $(80: 20, v / v)$ extracts were re-dissolved in water to obtain stock solutions of $8 \mathrm{mg} / \mathrm{ml}$, and then submitted to further dilutions. Four human tumor cell lines were tested: MCF-7 (breast adenocarcinoma), NCI-H460 (non-small cell lung carcinoma), HeLa (cervical carcinoma) and HepG2 (hepatocellular carcinoma). Sulforhodamine B assay was performed according to a procedure previously described by the authors (Barros et al., 2013). For evaluation of the cytotoxicity in non-tumor cells, a cell culture (named as PLP2) was prepared from a freshly harvested porcine liver obtained from a local slaughterhouse, according to a procedure established by the authors (Abreu et al., 2011). Ellipticine was used as positive control and the results were expressed in $\mathrm{GI}_{50}$ values (concentration that inhibited $50 \%$ of the net cell growth).

\subsubsection{Antibacterial activity}

The antibacterial activity was determined in the methanol/water $(80: 20, v / v)$ extracts, which were re-dissolved in water in order to obtain a stock solution of $100 \mathrm{mg} / \mathrm{ml}$, and then submitted to further dilutions. The protocol for antibacterial assays was previously described by Dias et al. (2016). In summary, the microorganisms used were multiresistant clinical isolates (urine and expectoration) as follows: Gram-negative bacteria (Escherichia coli ESBL (extended spectrum of beta-lactamase), Klebsiella pneumoniae, K. pneumoniae ESBL, Morganella morganii and Pseudomonas aeruginosa) and Gram-positive bacteria (MRSA-methicillin-resistant Staphylococcus aureus, MSSA-methicillinsusceptible $S$. aureus, Listeria monocytogenes and Enterococcus faecalis). Minimum inhibitory concentrations (MIC) were determined following the methodology proposed by Kuete, Ango et al. (2011) and Kuete, Justin et al. (2011). MIC was defined as the lowest concentration that inhibits the visible bacterial growth. The antibiotic susceptibility profile of the bacteria was previously described (Dias et al., 2016). The antibiotic concentrations applied are presented as Supplementary Material (Table S1).

\subsection{Statistical analysis}

Three samples were used for each group and all the assays were carried out in triplicate. The results were expressed as mean values and standard deviation (SD). Statistical analysed was performed using oneway analysis of variance (ANOVA) followed by Tukey's HSD Test with $p=0.05$. When necessary, a Student's $t$-test was used to determine the 
Table 2

Quantification of phenolic compounds (non-anthocyanin and anthocyanin) in the hydromethanolic extracts of grape pomace (mean \pm standard deviation).

\begin{tabular}{|c|c|c|c|c|}
\hline Peak & Tentative identification & Skins & Seeds & Mixtures \\
\hline \multicolumn{5}{|c|}{ Non-anthocyanin phenolic compounds ( $\mu \mathrm{g} / \mathrm{g}$ extract) } \\
\hline 1 & Gallic acid $^{1}$ & $104 \pm 3^{\mathrm{c}}$ & $313 \pm 1^{\mathrm{a}}$ & $146 \pm 1^{\mathrm{b}}$ \\
\hline 2 & Galloyl glucose ${ }^{1}$ & nd & $293 \pm 4$ & nd \\
\hline 3 & Catechin $^{2}$ & nd & $149 \pm 2$ & nd \\
\hline 4 & $\beta$-Type (epi)catechin dimer ${ }^{3}$ & nd & $803 \pm 24$ & nd \\
\hline 5 & Epicatechin $^{3}$ & nd & $984 \pm 5$ & $\operatorname{tr}$ \\
\hline 6 & $\beta$-Type (epi)catechin trimer ${ }^{3}$ & nd & $718 \pm 18$ & nd \\
\hline 7 & $p$-Coumaric acid hexoside ${ }^{4}$ & $729 \pm 2^{*}$ & nd & $434.0 \pm 0.1^{*}$ \\
\hline 8 & $\beta$-Type (epi)catechin tetramer ${ }^{3}$ & nd & $840.9 \pm 0.3$ & nd \\
\hline 9 & $p$-Coumaric acid hexoside ${ }^{4}$ & $1092 \pm 8^{*}$ & nd & $563 \pm 3^{*}$ \\
\hline 10 & $\beta$-Type (epi)catechin dimer ${ }^{3}$ & nd & $690 \pm 26$ & nd \\
\hline 11 & $\beta$-Type (epi)catechin trimer ${ }^{3}$ & nd & $678 \pm 3$ & nd \\
\hline 12 & $\beta$-Type (epi)catechin trimer ${ }^{3}$ & nd & $575 \pm 10$ & $631 \pm 6$ \\
\hline 13 & $\beta$-Type (epi)catechin dimer ${ }^{3}$ & nd & $1467 \pm 14$ & nd \\
\hline 14 & $\beta$-Type (epi)catechin tetramer ${ }^{3}$ & nd & $803 \pm 41$ & $1035 \pm 4$ \\
\hline 15 & $\beta$-Type (epi)catechin tetramer ${ }^{3}$ & nd & $580 \pm 35$ & nd \\
\hline 16 & Quercetin-glucoronide $^{5}$ & $343.5 \pm 0.1^{\mathrm{c}}$ & $253 \pm 2^{b}$ & $889 \pm 1^{\mathrm{a}}$ \\
\hline 17 & Laricitrin-3-O-galactoside ${ }^{5}$ & $280 \pm 4^{c}$ & $308 \pm 2^{\mathrm{a}}$ & $292 \pm 3^{b}$ \\
\hline 18 & Quercetin-3-O-glucoside ${ }^{5}$ & $298 \pm 0.1^{*}$ & nd & $257.1 \pm 0.5^{*}$ \\
\hline 19 & Syringetin-3-O-galactoside ${ }^{5}$ & $444 \pm 5^{c}$ & $259 \pm 2^{b}$ & $284 \pm 2^{\mathrm{a}}$ \\
\hline 20 & Laricitrin-3-O-rhamnose-7-O-trihydroxycinnamic acid ${ }^{5}$ & $344 \pm 0.6^{\mathrm{c}}$ & $256 \pm 1^{\mathrm{a}}$ & $282 \pm 3^{b}$ \\
\hline 21 & Syringetin rutinoside derivative ${ }^{5}$ & $269.4 \pm 0.6^{\mathrm{b}}$ & $247 \pm 1^{\mathrm{b}}$ & $249 \pm 3^{\mathrm{a}}$ \\
\hline TF30 & & nd & $8287 \pm 39^{*}$ & $2358 \pm 4^{*}$ \\
\hline TFO & & $1979 \pm 1^{a}$ & $1323 \pm 7^{c}$ & $1682 \pm 15^{b}$ \\
\hline TPA & & $1924 \pm 13^{\mathrm{a}}$ & $606 \pm 3^{c}$ & $1340 \pm 10^{b}$ \\
\hline TPC & & $3903 \pm 15^{c}$ & $10,216 \pm 35^{\mathrm{a}}$ & $5380 \pm 21^{b}$ \\
\hline \multicolumn{5}{|c|}{ Anthocyanin phenolic compounds ( $\mu \mathrm{g} / \mathrm{g}$ extract) } \\
\hline 22 & Malvidin-hexoside ${ }^{6}$ & $0.783 \pm 0.001^{\mathrm{a}}$ & $0.010 \pm 0.001^{c}$ & $0.30 \pm 0.01^{\mathrm{b}}$ \\
\hline 23 & Malvidin-acetylhexoside ${ }^{6}$ & $0.192 \pm 0.002^{*}$ & nd & $0.057 \pm 0.001^{*}$ \\
\hline 24 & Delphinidin-rutinoside ${ }^{7}$ & $1.60 \pm 0.08^{*}$ & nd & $0.366 \pm 0.002^{*}$ \\
\hline 25 & Malvidin-dihexoside ${ }^{6}$ & $0.267 \pm 0.003^{*}$ & nd & $0.067 \pm 0.001^{*}$ \\
\hline 26 & Petunidin-rutinoside ${ }^{7}$ & $2.65 \pm 0.03^{*}$ & nd & $0.72 \pm 0.04^{*}$ \\
\hline 27 & Peonidin-rutinoside ${ }^{8}$ & $0.115 \pm 0.005^{*}$ & nd & $0.048 \pm 0.001^{*}$ \\
\hline 28 & Malvidin-rutinoside ${ }^{6}$ & $2.335 \pm 0.0001^{\mathrm{a}}$ & $0.024 \pm 0.001^{\mathrm{c}}$ & $0.70 \pm 0.01^{\mathrm{b}}$ \\
\hline TA & & $7.9 \pm 0.1^{\mathrm{a}}$ & $0.034 \pm 0.001^{\mathrm{c}}$ & $2.25 \pm 0.06^{b}$ \\
\hline
\end{tabular}

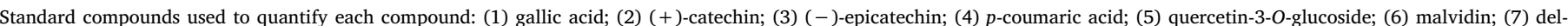

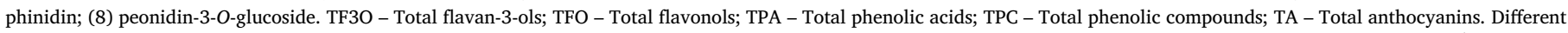

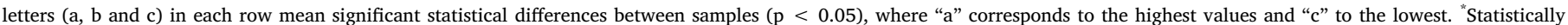
different values, Student's $t$-test $p$-value $<0.001$. nd- not detected, $\operatorname{tr}-\operatorname{traces}$.

significant difference between less than three different samples, with $p=0.05$. Furthermore, a Pearson's correlation analysis between the bioactivities and all the sum contents of the analysed compounds (total flavan-3-ols, total flavonols, total phenolic acids, total non-anthocyanin phenolic compounds and total anthocyanin phenolic compounds) was carried out, with a 95\% confidence level. These analyses were carried out using IBM SPSS Statistics for Windows, Version 23.0. (IBM Corp., Armonk, New York, USA).

\section{Results and discussion}

\subsection{Phenolic compounds profile}

Twenty eight phenolic compounds (non-anthocyanin and anthocyanin) were tentatively identified in the methanol/water $(80: 20, v / v)$ extracts prepared from grape pomace mixture, seeds and skins (Table 1): eleven flavan-3-ols (catechin and epicatechin derivatives and proanthocyanins), seven anthocyanins (malvidin, delphinidin, petunidin and peonidin derivatives), six flavonols (quercetin, laricitrin and syringetin derivatives), two hydroxybenzoic acid and two hydroxicinnamic acid derivatives. Table 2 presents the quantification of the phenolic compounds present in all extracts. An exemplificative phenolic profile of the hydromethanolic extracts obtained from grape pomace seeds is presented in Fig. 2.

Flavan-3-ols were the main family of phenolic compounds present in the hydromethanolic extracts of grape pomace mixture and seeds. This group was not detected in the skins sample. Peaks 3 and 5 were positively identified as (+)-catechin and ( - )-epicatechin, respectively, by comparison with commercial standards taking into account their retention time, mass and UV-vis spectra. Peaks 4, 10 and $13\left([\mathrm{M}-\mathrm{H}]^{-}\right.$ at $m / z$ 577) presented $\mathrm{MS}^{2}$ fragments at $\mathrm{m} / z$ 451, 425, and 407 ( $-126 \mathrm{mu},-152 \mathrm{mu}$ and $-152-18 \mathrm{mu}$, respectively) and also $\mathrm{m} / \mathrm{z} 289$ and 287, coherent with the loss of two (epi)catechin units, being therefore tentatively identified as B-type (epi)catechin dimers. On the other hand, peaks 6,11 and $12\left([\mathrm{M}-\mathrm{H}]^{-}\right.$at $\left.m / z 865\right)$ and 8,14 and 15 $\left([\mathrm{M}-\mathrm{H}]^{-}\right.$at $m / z$ 1153), were assigned as B-type (epi)catechin trimers and tetramers, respectively (Barros et al., 2015; Santos-Buelga et al., 1995).

Flavanol derivatives were the main phenolic compounds found in the hydromethanolic extracts of skins (second in seeds and mixture samples), but very close to the amount of phenolic acids. Quercetin, laricitrin and syringetin derivatives were the most abundant molecules. Peaks 16 and 18 were tentatively identified as quercetin-glucuronide $\left([\mathrm{M}-\mathrm{H}]^{-}\right.$at $\left.m / z 477\right)$ and quercetin-3-O-glucoside $\left([\mathrm{M}-\mathrm{H}]^{-}\right.$at $m / z$ 463) both realising an $\mathrm{MS}^{2}$ fragment at $\mathrm{m} / \mathrm{z} 301$ (glucoronyl and glycosil moieties, loss of -176 and -162 mu, respectively). Peak 18 was coherent with the commercial standards (retention time, mass and UV-vis). Peaks 17 and 20 were tentatively identified as laricitrin derivatives, where peak $17\left([\mathrm{M}-\mathrm{H}]^{-}\right.$at $m / z$ 493) released a unique $\mathrm{MS}^{2}$ fragment at $m / z 331$, corresponding to the loss of an galactosyl moiety $(-162 \mathrm{mu})$, being assigned as laricitrin-3-O-galactoside, due to its previous description in grape pomace (Downey and Rochfort, 2008; Flamini, 2013). Peak $20\left([\mathrm{M}-\mathrm{H}]^{-}\right.$at $\left.m / z 655\right)$ was tentatively identified as laricitrin-3-O-rhamnose-7-O-trihydroxycinnamic acid by its 


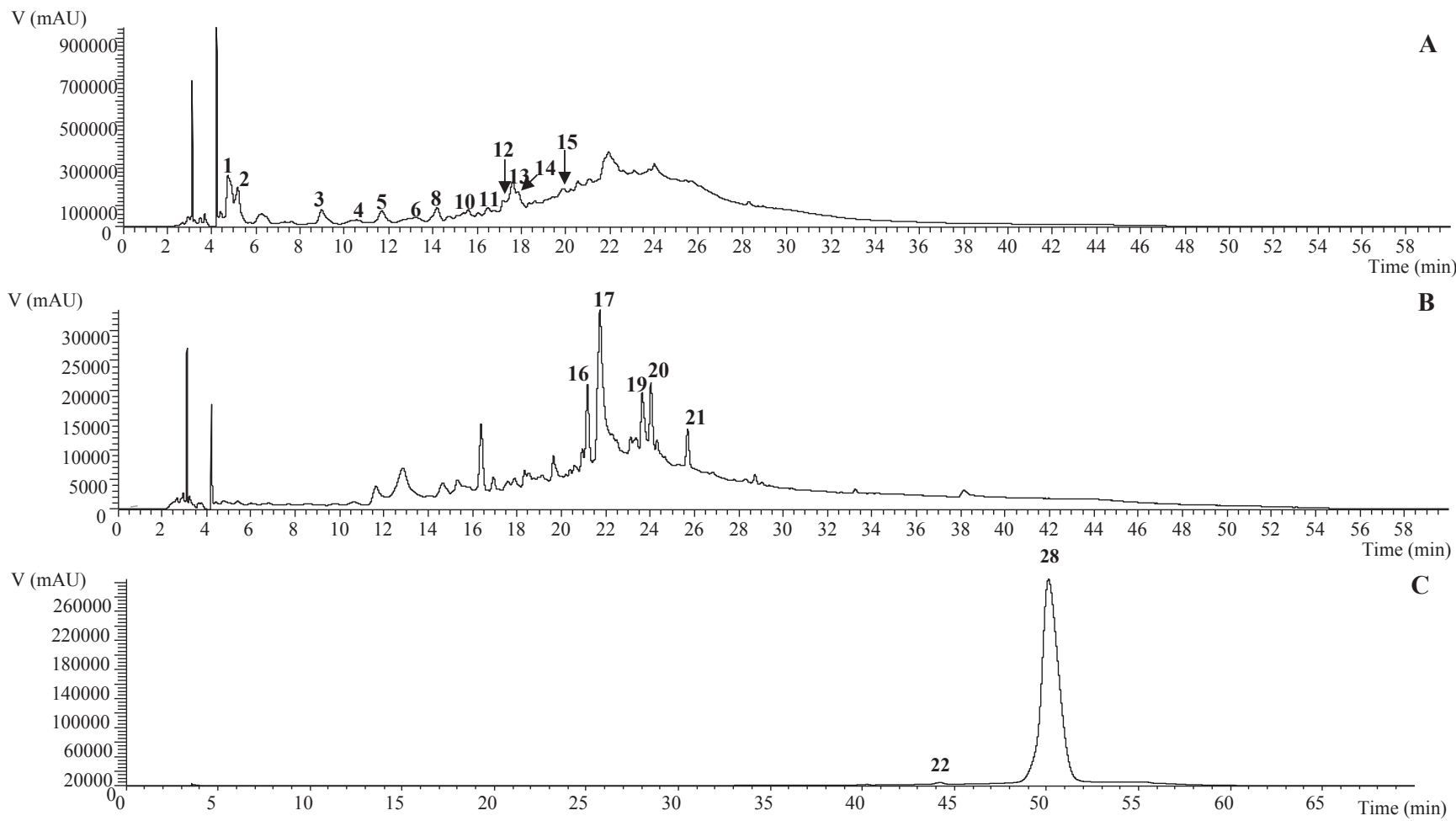

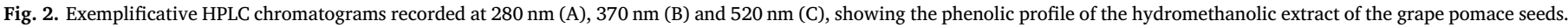

UV-vis spectrum and mass fragmentation, being previously described in grape skins originated from Australia (Downey \& Rochfort, 2008). Peaks 19 and 21 were tentatively identified as syringetin derivatives. Peak $19\left([\mathrm{M}-\mathrm{H}]^{-}\right.$at $m / z$ 507) presented a $\mathrm{MS}^{2}$ fragment at $m / z 345$ (loss of an hexosyl moiety, $-162 \mathrm{mu}$ ) corresponding to the aglycone syringetin, being assigned as syringetin-3-O-galactoside, due to its previous description in grape skins (Downey \& Rochfort, 2008). Peak $21\left([\mathrm{M}-\mathrm{H}]^{-}\right.$at $\left.m / z 745\right)$ presented an $\mathrm{MS}^{2}$ fragments' pattern at $m / z$ 653, 419 and 345, nevertheless, it was not possible to conclude about the exact identification of this compound; being identified as a syringetin rutinoside derivative.

Two p-coumaric acid hexosides (peaks 7 and 9) were tentatively identified because both presented a molecular ion $[\mathrm{M}-\mathrm{H}]^{-}$at $m / z 325$ and a unique $\mathrm{MS}^{2}$ fragment at $\mathrm{m} / \mathrm{z} 163$ (p-coumaric acid), corresponding to the loss of an hexosyl moiety (162 mu). Peak 9 was identified as the major compound in skins samples, which has been previously reported in literature (Flamini, 2013; Kammerer, Claus, Carle, \& Schieber, 2004; Núñe, Monagas, Gomez-Cordovés, \& Bartolomé, 2004; Perestrelo et al., 2012; Pomar, Novo, \& Masa, 2005; Püssa, Floren, Kuldkepp, \& Raal, 2006).

Peaks 1 and 2 corresponded to hydroxybenzoic acid derivatives, where peak 1 was identified as gallic acid, by comparing its characteristic with the commercial standard, and peak $2\left([\mathrm{M}-\mathrm{H}]^{-}\right.$at $m / z$ 331) was tentatively identified as galloyl glucose, a monomeric gallotannin linked to a glucose moiety, presenting a molecular ion and fragmentation pattern corresponding to this identification (Flamini, 2013; Monagas, Gómez-Cordovés, Bartolomé, Laureano, \& Silva, 2003). The three samples presented different major compounds, despite presenting similar profiles. $p$-Coumaric acid (peak 9, $1092 \mu \mathrm{g} / \mathrm{g}$ extract) was the major compound found in skins, while $\beta$-type (epi)catechin dimer (peak 13, $1467 \mu \mathrm{g} / \mathrm{g}$ ) was the main compound identified in seeds and $\beta$-type (epi)catechin tetramer (peak 14, $1035 \mu \mathrm{g} / \mathrm{g}$ extract) was the main molecule in mixtures. Seeds were the part that presented the highest concentration in phenolic compounds $(10,216 \mu \mathrm{g} / \mathrm{g}$ extract).

Finally, seven different anthocyanin compounds were identified in the hydromethanolic extracts, being malvidin derivatives the major group of molecules present (Fig. 2C). Peaks 22, 23, 25 and 28 $\left([\mathrm{M}-\mathrm{H}]^{-}\right.$at $m / z 493,535,655$ and 639 , respectively) released a unique $\mathrm{MS}^{2}$ fragments at $\mathrm{m} / \mathrm{z} 331$ corresponding to the loss of hexoside (162 mu), acetylhexoside (204 mu), dihexoside (324 mu) and rutinoside (308 mu) moieties, respectively, being assigned as malvidinhexoside, malvidin-acetylhexoside, malvidin-dihexoside and malvidinrutinoside, respectively. Malvidin-rutinoside (peak 28) was the main compound found in seeds and skins, while petunidin-rutinoside was the major compound found in mixtures. Peaks 24,26 and $27\left([\mathrm{M}-\mathrm{H}]^{-}\right.$at $\mathrm{m} / \mathrm{z} 611,625$ and 609, respectively), all releasing a unique $\mathrm{MS}^{2}$ fragment corresponding to the aglycone delphinidin $(\mathrm{m} / \mathrm{z} 303)$, petunidin $(\mathrm{m} / \mathrm{z} 317)$ and peonidin $(\mathrm{m} / \mathrm{z} 301)$, bearing $308 \mathrm{mu}$, corresponding to the loss of a rutinosyl moiety, were identified as delphinidin-rutinoside, petunidin-rutinoside and peonidin-rutinoside, respectively. The presence of these compounds in grape pomace has been extensively described (Bakker, Preston, \& Timberlake, 1986; Downey \& Rochfort, 2008; KajdŽanoska, Gjamovski, \& Stefova, 2010; Kammerer et al., 2004; Liang et al., 2008; Núñe et al., 2004; Pomar et al., 2005; Püssa et al., 2006; Sandhu \& Gu, 2010). Skins showed the highest values of anthocyanin compounds ( $7.9 \mu \mathrm{g} / \mathrm{g}$ extract), followed by mixtures, while only two anthocyanins in very low concentration were found in seeds.

\subsection{Bioactivity of the hydromethanolic extracts}

Results regarding antioxidant, cytotoxic and antibacterial activities of the methanol/water $(80: 20, v / v)$ extracts prepared from grape pomace mixture, seeds and skins are shown in Table 3. Overall, seeds gave the lowest $\mathrm{EC}_{50}$ values in all the assays performed, DPPH scavenging activity, reducing power, $\beta$-carotene bleaching inhibition and TBARS inhibition $(23,110,208$ and $49.6 \mu \mathrm{g} / \mathrm{ml}$, respectively), therefore revealing a higher antioxidant activity than skins and mixtures. Skins revealed the highest $\mathrm{EC}_{50}$ values (lowest antioxidant activity), so it can be concluded that the antioxidant activity of the mixtures is mainly due to the contribution of the seeds rather than skins. The results proved to be strongly correlated $\left(R^{2}\right)$ with the presence of phenolic compounds (non-anthocyanins and anthocyanins). The determination coefficients 
Table 3

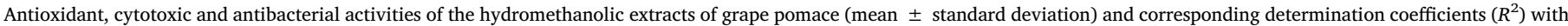
the phenolic compound families.

\begin{tabular}{|c|c|c|c|c|c|c|c|c|}
\hline \multirow[t]{2}{*}{ Antioxidant activity $\mathrm{EC}_{50}$ values $(\mu \mathrm{g} / \mathrm{ml})$} & \multicolumn{3}{|c|}{ Hydromethanolic extracts } & \multirow[t]{2}{*}{ TF3O } & \multicolumn{4}{|c|}{ Determination Coefficient $R^{2}$} \\
\hline & Skins & Seeds & Mixtures & & TFO & TPA & TPC & TA \\
\hline DPPH scavenging activity & $563 \pm 14^{\mathrm{a}}$ & $23 \pm 1^{\mathrm{c}}$ & $123 \pm 5^{b}$ & 0.983 & 0.983 & 0.917 & 0.883 & 0.817 \\
\hline Reducing power & $488 \pm 10^{\mathrm{a}}$ & $110 \pm 4^{\mathrm{c}}$ & $262 \pm 1^{\mathrm{b}}$ & 0.881 & 0.850 & 0.883 & 0.917 & 0.950 \\
\hline$\beta$-carotene bleaching inhibition & $782 \pm 23^{\mathrm{a}}$ & $208 \pm 9^{c}$ & $362 \pm 19^{b}$ & 0.949 & 0.950 & 0.917 & 0.883 & 0.850 \\
\hline TBARS inhibition & $629 \pm 3^{\mathrm{a}}$ & $49.6 \pm 0.3^{\mathrm{c}}$ & $97 \pm 1^{b}$ & 0.932 & 0.850 & 0.983 & 0.817 & 0.850 \\
\hline \multicolumn{9}{|l|}{ Cytotoxic activity $\mathrm{GI}_{50}$ values $(\mu \mathrm{g} / \mathrm{ml})$} \\
\hline MCF-7 (human breast adenocarcinoma) & $>400$ & $352 \pm 21^{*}$ & $332 \pm 20^{*}$ & 0.931 & 0.915 & 0.983 & 0.848 & 0.915 \\
\hline NCI-H460 (human non-small lung carcinoma) & $>400$ & $>400$ & $>400$ & - & - & - & - & - \\
\hline HeLa (human cervical carcinoma) & $>400$ & $253 \pm 26$ & $>400$ & - & - & - & - & - \\
\hline HepG2 (human hepatocellular carcinoma) & $>400$ & $>400$ & $>400$ & - & - & - & - & - \\
\hline PLP2 (non-tumor porcine liver cells) & $>400$ & $>400$ & $>400$ & - & - & - & - & - \\
\hline \multicolumn{9}{|l|}{ Antibacterial activity MIC values $(\mathrm{mg} / \mathrm{ml})$} \\
\hline \multicolumn{9}{|l|}{ Gram negative } \\
\hline Escherichia coli ESBL & $>20$ & 20 & 20 & 0.836 & 0.822 & 0.822 & 0.822 & 0.822 \\
\hline Klebsiella pneumoniae & $>20$ & 10 & $>20$ & - & - & - & - & - \\
\hline Klebsiella pneumoniae ESBL & $>20$ & 10 & $>20$ & - & - & - & - & - \\
\hline Morganella morganii & $>20$ & 20 & 10 & 0.965 & 0.949 & 0.949 & 0.949 & 0.949 \\
\hline Pseudomonas aeruginosa & $>20$ & 20 & 20 & 0.836 & 0.822 & 0.822 & 0.822 & 0.822 \\
\hline \multicolumn{9}{|l|}{ Gram positive } \\
\hline Enterococcus faecalis & $>20$ & 2.5 & 10 & 0.482 & 0.474 & 0.474 & 0.474 & 0.474 \\
\hline Listeria monocytogenes & $>20$ & 10 & 20 & 0.482 & 0.474 & 0.474 & 0.474 & 0.474 \\
\hline MRSA $^{*}$ & 20 & 5 & 10 & 0.965 & 0.949 & 0.949 & 0.949 & 0.949 \\
\hline MSSA & 20 & 5 & 10 & 0.965 & 0.949 & 0.949 & 0.949 & 0.949 \\
\hline
\end{tabular}

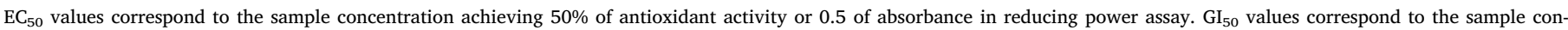
centration achieving 50\% of growth inhibition in human tumor cell lines or in liver primary culture PLP2.

Trolox EC 50 values: $62.98 \mu \mathrm{g} / \mathrm{ml}$ (DDPH), $45.71 \mu \mathrm{g} / \mathrm{ml}$ (reducing power), $10.25 \mu \mathrm{g} / \mathrm{ml}$ ( $\beta$-carotene bleaching inhibition) and $3.73 \pm 1.9 \mu \mathrm{g} / \mathrm{ml}$ (TBARS inhibition).

Ellipticine $\mathrm{GI}_{50}$ values: $1.21 \mathrm{mg} / \mathrm{ml}$ (MCF-7), $1.03 \mathrm{mg} / \mathrm{ml}$ (NCI-H460), $0.91 \mathrm{mg} / \mathrm{ml}$ (HeLa), $1.10 \mathrm{mg} / \mathrm{ml}$ (HepG2) and 2.29 mg/ml (PLP2).

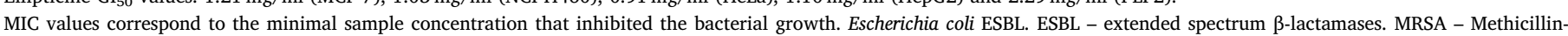

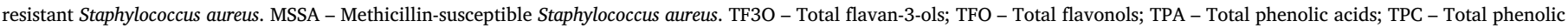

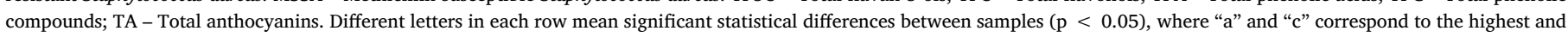
lowest values, respectively. "Statistically different values, Student's $t$-test $p$-value $<0.001$.

ranged from $R^{2}=0.817$ (TBARS inhibition assay and total phenolic compounds) to $R^{2}=0.983$ (DPPH scavenging activity and total flavan3-ols, and total flavonols; and TBARS inhibition and total phenolic acids). The antioxidant activity of Vitis vinifera has been previously reported by other authors, such as Bartolomé et al. (2004) that studied the antioxidant activity of red grape skins (Vitis vinifera, var. Cabernet Sauvignon, Graciano and Tempranillo) originated from Spain. Murthy et al. (2002) investigated the antioxidant activity of Vitis vinifera grape pomace (var. Bangalore blue) from Indian states. Xia et al. (2010) reported similar $\mathrm{EC}_{50}$ values for DPPH scavenging activity in grape pomace mixture, seeds and skins $\left(\mathrm{EC}_{50} \sim 200 \mu \mathrm{g} / \mathrm{ml}\right)$, which was not the case of the results obtained in the present study.

The skins were not able to inhibit the growth of any of the tested carcinoma cell lines $\left(\mathrm{GI}_{50}>400 \mu \mathrm{g} / \mathrm{ml}\right)$, while the seeds inhibited the growth of breast carcinoma (MCF-7, $\mathrm{GI}_{50}=352 \mu \mathrm{g} / \mathrm{ml}$ ) and cervical carcinoma (HeLa, $\mathrm{GI}_{50}=253 \mu \mathrm{g} / \mathrm{ml}$ ) cell lines (Table 3 ). However, the mixtures were only effective against MCF-7 line $\left(\mathrm{GI}_{50}=332 \mu \mathrm{g} / \mathrm{ml}\right)$, which evidences that the presence of skins is not favourable for cytotoxic effects on HeLa cell line. It should be emphasized that the samples were not toxic for non-tumor cells of porcine liver (PLP2). The cytotoxicity observed in MCF-7 cell line proved to be strongly correlated with the presence of phenolic compounds ranging from $R^{2}=0.848$ (total phenolic compounds) to $R^{2}=0.983$ (total phenolic acids). Other authors described that the presence of polyphenols induces apoptosis of prostate tumor cells, and suppresses the cellular proliferation of intestinal crypts as also gastric and colonic cancer cells in vitro, suppressing mitosis and increasing apoptosis (Gee, Hara, \& Johnson, 2002; Wang \& Stoner, 2008).

Results of the antimicrobial activity are also presented in Table 3. The lowest MIC values were observed in seeds and against Gram- positive bacteria, Enterococcus faecalis, MRSA and MSSA (2.5, 5 and $5 \mathrm{mg} / \mathrm{ml}$, respectively). For Gram-negative bacteria, seeds also exhibited the lowest MIC values against $K$. pneumoniae and $K$. pneumoniae ESBL $(10 \mathrm{mg} / \mathrm{ml}$ for both bacteria). The skins showed the poorest antibacterial activity, revealing MIC values $>20 \mathrm{mg} / \mathrm{ml}$ for almost all bacteria strains, and $20 \mathrm{mg} / \mathrm{ml}$ for MRSA and MSSA. The antibacterial activity proved to have a strong correlation with the presence of phenolic compounds, mainly in M. morganii, MRSA and MSSA for all the family of compounds, ranging from $R^{2}=0.949$ (total flavonols, total phenolic acids, total phenolic compounds and total anthocyanins) to $R^{2}=0.965$ (total flavan-3-ols). Jayaprakasha et al. (2003), described similar results with grape seeds extracts (var. Bangalore blue) with lower MIC values against Gram-positive bacteria. Furthermore, Anastasiadi, Chorianopoulos, Nychas, and Karoutounian (2009) tested extracts of Vitis vinifera grape pomace (var. Mandilaria, Voidomato, Asyrtiko and Aidani) against Listeria monocytogenes, and described that the seed extracts were significantly more antimicrobial than stems.

\section{Conclusions}

The seeds showed the highest concentrations of phenolic compounds (mainly a $\beta$-type (epi)catechin dimer), as also the highest antioxidant (in all the performed assays), cytotoxic (for MCF-7 and HeLa lines, without toxicity for non-tumor cells) and antibacterial (against Gram-positive bacteria) activities. Otherwise, the skins exhibited the highest amounts of anthocyanins, mainly due to the presence of petunidin-rutinoside and malvidin-rutinoside. It also revealed higher levels of $p$-coumaric acid hexoside, which was the main compound found; nonetheless the flavan-3-ol derivatives were not detected in this sample. Even if more consistent results could be expected for some 
parameters found in the mixture sample, when compared to seeds and skins, the contribution magnitude of each cannot be predicted because their mass percentage in the mixture is unknown. Nonetheless, the antioxidant activity of grape pomace mixture is more related to the presence of seeds rather than skins. Strong correlation results were observed between the presence of phenolic compounds and all the studied bioactivities, except for the results obtained for the antimicrobial activity against $E$. faecalis and $L$. monocytogenes.

The bio-residues resulting from the wine industry are sometimes discarded. This study reveals that these wastes are good sources of important bioactive molecules, namely phenolic compounds, with high antioxidant and antibacterial activities, as also moderate cytotoxic properties. It is extremely important to add value to this type of byproduct in order to increment their use in the extraction of biomolecules for applications in food, pharmaceutical and cosmetic industries.

\section{Acknowledgements}

The authors thank the financial support to CIMO (UID/AGR/00690/ 2013) and Associate Laboratory LSRE-LCM, Instituto Politécnico de Bragança (project POCI-01-0145-FEDER-006984) funded by European Regional Development Fund (ERDF) through Programmes PT2020 and COMPETE2020 - Programa Operacional Competitividade e Internacionalização (POCI) - and by national funds through FCT Fundação para a Ciência e a Tecnologia, also funding the contracts of R.C. Calhelha and L. Barros. To the FEDER-Interreg España-Portugal programme for financial support through the project 0377_Iberphenol_6_E.

\section{Appendix A. Supplementary data}

Supplementary data associated with this article can be found, in the online version, at http://dx.doi.org/10.1016/j.foodchem.2018.01.163.

\section{References}

Abreu, R. M. V., Ferreira, I. C. F. R., Calhelha, R. C., Lima, R. T., Vasconcelos, M. H., Adega, F., ... Queiroz, M. J. R. P. (2011). Anti-hepatocellular carcinoma activity using human HepG2 cells and hepatotoxicity of 6-substituted methyl 3-aminothieno[3,2-b] pyridine-2- carboxylate derivatives: In vitro evaluation, cell cycle analysis and QSAR studies. European Journal of Medicinal Chemistry, 46(12), 5800-5806. http://dx.doi. org/10.1016/j.ejmech.2011.09.029.

Anastasiadi, M., Chorianopoulos, N. G., Nychas, G. J. E., \& Karoutounian, S. A. (2009) Antilisterial activities of polyphenol-rich extracts of grapes and vinification byproducts. Journal of Agriculture and Food Chemistry, 57(2), 457-463. http://dx.doi. org/10.1021/jf8024979.

Bakker, J., Preston, N. W., \& Timberlake, C. F. (1986). The determination of anthocyanins in aging red wines: Comparison of hplc and spectral methods. Retrieved from American Journal of Enology and Viticulture, 37(2), 121-126. http://www.ajevonline. org/content/37/2/121.abstract.

Barros, L., Calhelha, R., Queiroz, M. J. R. P., Santos-Buelga, C., Santos, E. A., Regis, W. C. B., \& Ferreira, I. C. F. R. (2015). The powerful in vitro bioactivity of Euterpe oleracea Mart. seeds and related phenolic compounds. Industrial Crops and Products, 76, 318-322. http://dx.doi.org/10.1016/j.indcrop.2015.05.086.

Barros, L., Pereira, E., Calhelha, R. C., Dueñas, M., Carvalho, A. M., Santos-Buelga, C., \& Ferreira, I. C. F. R. (2013). Bioactivity and chemical characterization in hydrophilic and lipophilic compounds of Chenopodium ambrosioides L. Journal of Functional Foods, 5(4), 1732-1740. http://dx.doi.org/10.1016/j.jff.2013.07.019.

Bartolomé, B., Nuñez, V., Monagas, M., \& Gómez-Cordovés, C. (2004). In vitro antioxidant activity of red grape skins. European Food Research and Technology, 218(2), 173-177. http://dx.doi.org/10.1007/s00217-003-0833-x.

Bessada, S. M. F., Barreira, J. C. M., Barros, L., Ferreira, I. C. F. R., \& Oliveira, M. B. P. P. (2016). Phenolic profile and antioxidant activity of Coleostephus myconis (L.) Rchb. f.: An underexploited and highly disseminated species. Industrial Crops \& Products, 89, 45-51. http://dx.doi.org/10.1016/j.indcrop.2016.04.065

Caleja, C., Ribeiro, A., Barreiro, M. F., \& Ferreira, I. C. F. R. (2017). Phenolic compounds as nutraceuticals or functional food ingredients. Current Pharmaceutical Design, 23(19), 2787-2806. http://dx. doi.org/10.2174/1381612822666161227153906.

Dias, M. I., Barros, L., Morales, P., Cámara, M., Alves, M.-J., Oliveira, M. B. P., ... Ferreira, I. C. F. R. (2016). Wild Fragaria vesca L. fruits: a rich source of bioactive phytochemicals. Food \& Function, 4523-4532, http://dx.doi.org/10.1039/c6fo01042c.

Downey, M. O., \& Rochfort, S. (2008). Simultaneous separation by reversed-phase highperformance liquid chromatography and mass spectral identification of anthocyanins and flavonols in Shiraz grape skin. Journal of Chromatography A, 1201(1), 43-47. http://dx.doi.org/10.1016/j.chroma.2008.06.002.

Flamini, R. (2013). Recent applications of mass spectrometry in the study of grape and wine polyphenols. ISRN Spectroscopy, 2013, 45. http://dx.doi.org/10.1155/2013/
813563.

Gee, J. M., Hara, H., \& Johnson, I. T. (2002). Suppression of intestinal crypt cell proliferation and aberrant crypt foci by dietary quercetin in rats. Nutrition and Cancer, 43(2), 193-201. http://dx.doi.org/10.1207/S15327914NC432_10.

Gonçalves, G. A., Soares, A. A., Correa, R. C. G., Barros, L., Haminiuk, C. W. I., Peralta, R. M., ... Bracht, A. (2017). Merlot grape pomace hydroalcoholic extract improves the oxidative and inflammatory states of rats with adjuvant-induced arthritis. Journal of Functional Foods, 33, 408-418. http://dx.doi.org/10.1016/j.jff.2017.04.009.

Jayaprakasha, G. K., Selvi, T., \& Sakariah, K. K. (2003). Antibacterial-and-antioxidantproperties-of-GSE.pdf, pp. 117-122.

KajdŽanoska, M., Gjamovski, V., \& Stefova, M. (2010). HPLC-DAD-ESI-MSn identification of phenolic compounds in cultivated strawberries from Macedonia. Macedonian Journal of Chemistry and Chemical Engineering, 29(2), 181-194.

Kammerer, D., Claus, A., Carle, R., \& Schieber, A. (2004). Polyphenol screening of pomace from red and white grape varieties (Vitis vinifera L.) by HPLC-DAD-MS/MS. Journal of Agricultural and Food Chemistry, 52(14), 4360-4367. http://dx.doi.org/10.1021/ jf049613b.

Kuete, V., Ango, P. Y., Fotso, G. W., Kapche, G. D. W. F., Dzoyem, J. P., Wouking, A. G., ... Abegaz, B. M. (2011a). Antimicrobial activities of the methanol extract and compounds from Artocarpus communis (Moraceae). BMC Complementary and Alternative Medicine, 11(1), 42. http://dx.doi.org/10.1186/1472-6882-11-42.

Kuete, V., Justin, K., Louis, P. S., Bathelemy, N., Herve, M. P., Pantaleon, A., \& Bonaventure, T. N. (2011b). Antimicrobial activities of the methanol extract, frac tions and compounds from Ficus polita Vahl. (Moraceae). BMC Complementary and Alternative Medicine, 11, 6.

Liang, Z., Wu, B., Fan, P., Yang, C., Duan, W., Zheng, X., ... Li, S. (2008). Anthocyanin composition and content in grape berry skin in Vitis germplasm. Food Chemistry, 111(4), 837-844. http://dx.doi.org/10.1016/j.foodchem.2008.04.069.

Makris, D. P., Boskou, G., \& Andrikopoulos, N. K. (2007). Polyphenolic content and in vitro antioxidant characteristics of wine industry and other agri-food solid waste extracts. Journal of Food Composition and Analysis, 20(2), 125-132. http://dx.doi.org/ 10.1016/j.jfca.2006.04.010.

Melo, E. D. A., Maciel, M. I. S., Lima, V. L. A. G., Leal, F. L. L., Caetano, A. C. D. S., \& Nascimento, R. J. (2006). Capacidade antioxidante de hortaliças usualmente consumidas. Ciência E Tecnologia de Alimentos, 26(3), 639-644. http://dx.doi.org/10. 1590/S0101-20612006000300024.

Monagas, M., Gómez-Cordovés, C., Bartolomé, B., Laureano, O., \& Silva, J. M. R. (2003) Monomeric, oligomeric, and polymeric flavan-3-ol composition of wines and grape from Vitis vinifera L. Cv. Graciano, Tempranillo, and cabernet sauvignon. Journal of Agriculture and Food Chemistry, 51(22), 6475-6481. http://dx.doi.org/10.1021/ jf030325 +.

Murthy, K. N. C., Singh, R. P., \& Jayaprakasha, G. K. (2002). Antioxidant activities of grape Vitis vinifera pomace extracts. Journal of Agriculture and Food Chemistry, 50, 5909-5914.

Núñe, V., Monagas, M., Gomez-Cordovés, M. C., \& Bartolomé, B. (2004). Vitis vinifera L. cv. Graciano grapes characterized by its anthocyanin profile. Postharvest Biology and Technology, 31(1), 69-79. http://dx.doi.org/10.1016/S0925-5214(03)00140-6.

Perestrelo, R., Lu, Y., Santos, S. A. O., Silvestre, A. J. D., Neto, C. P., Câmara, J. S., \& Rocha, S. M. (2012). Phenolic profile of Sercial and Tinta Negra Vitis vinifera L. grape skins by HPLC-DAD-ESI-MS n: Novel phenolic compounds in Vitis vinifera L. grape. Food Chemistry, 135(1), 94-104. http://dx.doi.org/10.1016/j.foodchem.2012.04. 102.

Pomar, F., Novo, M., \& Masa, A. (2005). Varietal differences among the anthocyanin profiles of 50 red table grape cultivars studied by high performance liquid chromatography. Journal of Chromatography A, 1094(1-2), 34-41. http://dx.doi.org/10. 1016/j.chroma.2005.07.096.

Püssa, T., Floren, J., Kuldkepp, P., \& Raal, A. (2006). Survey of grapevine Vitis vinifera stem polyphenols by liquid chromatography-diode array detection-tandem mass spectrometry. Journal of Agriculture and Food Chemistry, 54(20), 7488-7494. http:// dx.doi.org/10.1021/jf061155e.

Rodríguez Montealegre, R., Romero Peces, R., Chacón Vozmediano, J. L., Martínez Gascueña, J., \& García Romero, E. (2006). Phenolic compounds in skins and seeds of ten grape Vitis vinifera varieties grown in a warm climate. Journal of Food Composition and Analysis, 19(6-7), 687-693. http://dx.doi.org/10.1016/j.jfca.2005. 05.003.

Sandhu, A. K., \& Gu, L. (2010). Antioxidant capacity, phenolic content, and profiling of phenolic compounds in the seeds, skin, and pulp of vitis rotundifolia (Muscadine Grapes) as determined by HPLC-DAD-ESI-MSn. Journal of Agricultural and Food Chemistry, 58(8), 4681-4692. http://dx.doi.org/10.1021/jf904211q.

Santos-Buelga, C., Francia-Aricha, E. M., \& Escribano-Bailón, M. T. (1995). Comparative flavan-3-ol composition of seeds from different grape varieties. Food Chemistry, 53(2), 197-201. http://dx.doi.org/10.1016/0308-8146(95)90788-9.

Scalbert, A., Manach, C., Morand, C., Rémésy, C., \& Jiménez, L. (2005). Dietary polyphenols and the prevention of diseases. Critical Reviews in Food Science and Nutrition, 45(4), 287-306. http://dx.doi.org/10.1080/1040869059096.

Terral, J. F., Tabard, E., Bouby, L., Ivorra, S., Pastor, T., Figueiral, I., ... This, P. (2010) Evolution and history of grapevine (Vitis vinifera) under domestication: New morphometric perspectives to understand seed domestication syndrome and reveal origins of ancient European cultivars. Annals of Botany, 105(3), 443-455. http://dx.doi. org $/ 10.1093 /$ aob/mcp298.

Wang, L. S., \& Stoner, G. (2008). Anthocyanins and their role in cancer prevention. Cancer Letters, 269(2), 281-290. http://dx.doi.org/10.1016/j.canlet.2008.05.020. Anthocyanins.

Xia, E., Deng, G., Guo, Y., \& Li, H. (2010). Biological activities of polyphenols from grapes. International Journal of Molecular Sciences, 11, 622-646 http://doi.org/ 10.1016/B978-0-12-398456-2.00005-0.

Yu, J., \& Ahmedna, M. (2013). Functional components of grape pomace: Their composition, biological properties and potential applications. International Journal of Food Science \& Technology. http://dx.doi.org/10.1111/j.1365-2621.2012.03197.x. 